\title{
Kurdish National Identity in the films of Yilmaz Guney and Bahmani Ghobadi
}

\author{
Lanja Najmaldin Karim \\ Department of English, College of Languages, University of Human Development. Sulaimani, Kurdistan Region - F.R. Iraq
}

\begin{abstract}
Kurdish identity in the works of Kurdish film makers, namely Bahmani Ghobadi and Yikmaz Guney, whose films established a unified Kurdish National Cinema beyond the borders and statelessness in a transnational space. This essay delineates the ways Kurdishness is expressed in the cinematic techniques of the two Kurdish film makers who used similar subtle techniques to incorporate their Kurdish identity into the films they made. The Kurds, as one of the largest stateless ethnic group in the Middle East have suffered violent oppression, state perpetuated discrimination, and exclusion. This essay draws on Hannah Arendt's The Origins of Totalitarianism, and Philip Rosen's essay in Theorizing National Cinema to explore how Yalmiz Guney and Bahmani Ghobadi presented the national identity of the characters to mark the films with a sense of Kurdishness. This essay further explores the construction of national identity and personhood specifically in Guney's Yol and Ghobadi's Turtles Can Fly to show how stateless people can easily become a subject of dehumanization by different nation states.
\end{abstract}

Index Terms - Statelessness, Identity, power, Kurdish, National Cinema.

\section{INTRODUCTION}

The discourse around Kurdish national cinema is still widely contested among critics. The Kurds as the largest stateless ethnic group have historically struggled to have a nationally recognized cinema labeled as Kurdish on an international stage. In the quest of what constitute national cinema, this essay delineates the works of Ghobadi and Guney as strictly Kurdish despite the fact that they are often mentioned within the frameworks of Iranian and Turkish national cinema due to Guney's Turkish citizenship and Ghobadi's Iranian citizenship. Kurdish cinema originally emerged from non-conventional places like war zones, exile, refugee camps and prison. Critics divided the emergence of Kurdish cinema periodically within certain socio-political changes that happened to the Kurds across the Middle East, the Caucuses, and the diaspora. (Kocer, 2014. P, 3)

The concept of National Cinema and how cinema can represent a nation is widely debated among the critics. There is not a single theory that all critics agree on based on which a film or a body of film can be labeled the national cinema of a given nation whether the nation has a state or stateless. Traditionally, the concept of Nation Cinema is understood to refer to a body of work that represent a nation state. The authors in Theorizing National Cinema, suggest national cinema is:

conceptualization of Selected 'national' films/texts themselves, the relationship between them, which be connected by a shared (general) symptom, an understanding of the 'nation' as an entity in synchronicity with its 'symptom'. And understanding of past or traditional 'symptoms', also known as history or historiography, which contribute to current systems and symptoms. These symptoms of intertextuality could refer to style, medium, content, narrative, narrative structure, costume, Mise-en-scène, character, background, cinematography. It could refer to cultural background of those who make the movie and cultural background of those in the movie, of spectatorship, of spectacle. (Willemen \& Valentina 2019, 5)

They believe that a set of criteria should be in place based on which a film can be evaluated as a national cinema, however, through the textuality of the film. In the case of minorities producing films is within a state in which the minorities do not have the privileged to freely express their cultural and linguistic signs and elements, the finding of those symptoms are almost always nuanced. Thus, film makers whose ethnicity or nationality has been denied for forcefully assimilated to the homogenous nation of a state had to look for methods and techniques to express their national identity in a less ostensible way.

In Cinema and Nation, Hjort and Mackenzie delineate a different kinds of national cinema that have emerged in different historical circumstances. They argue films can represent a nation that is separate from the nation state in which they are produced. However, historically films are labeled and attributed to the nation state from which the film was made or the nationality of the director or the language of the film. The complexity of attributing a film to the national cinema of a nation based on the place of the setting or the nationality of the director or the script writer, or the language of the film is not instrumental as films today made by Hollywood and Bollywood could contain all these categories and yet being attributed as Indian or American in the discourse.

Journal of University of Human Development

Volume 7 No. 3(2021); DOI: 10.21928/juhd.v7n3y2021.pp69-73

Regular research paper: Received 6 July 2021; Accepted 8 August 2021; Published 18 August 2021

Corresponding author's e-mail: lanja.karim@uhd.edu.iq

Copyright (C) 2021 Lanja Najmaldin Karim. This is an open access article distributed under the Creative Commons Attribution License (CC

BY-NC-ND 4.0) 
In Imagined Communities: Reflections on the Origins and Spread of Nationalism, the author claims a nation is the mapping of an imagined community in which its members share similar values and have a unified sense of belonging to a carved geo-political space. Nations can exist outside a state. In other words, stateless people can have a nation, therefor, nationhood is not dependent on statehood. And for this reason, a national cinema can be established to stateless ethnic or religious groups who have been historically marginalized by the state they live in. (Anderson, 2020. P, 2)

Arguably, Kurdish film makers have been able to establish a cinema that can be distinctly labeled as Kurdish especially in discourse. The establishment and evolution of Kurdish national cinema hurdled with numerous attempts of marginalization, exclusion, persecution and denial of the homogenous nation state of the four countries, Iraq, Iran, Syria and Turkey where Kurds mainly reside.

The first Kurdish film was made in Soviet Armenia in 1926, directed by Hamo Beknazarian under the name Zare. The film shows the life and existence of a Kurdish Yazidi minority group in Soviet Armenia who struggle with the tyranny of a feudal system. The film was made in 1926 when adding sound to film technologies was too limited thus all interaction between the characters are only understood via the moving images. Beknazarian was not a Kurd and his main intention was to portray the Kurds in a negative spectrum, therefore, the film depicts the Kurds as an ignorant illiterate ethnic group living under the tyranny of their feudal leaders. The film is filled with racist stereotypical ideas against the Kurdish Yazidis who lived in Armenia around that time. The characters of this film all wear Kurdish traditional costumes and their Kurdish identity is put on screen without any scrutiny. Up to the date, many critics refuse to categorize this film as a Kurdish film despite the conspicuous representation of Kurdish culture claiming the director's attention was only to depict the Kurds as a barbaric ignorant ethnic group.

Later in 1950s- 1984, Yilmaz Guney, an ethnic Kurd, started making films in Turkish. His films soon gained popularity across Turkey and received international acknowledgement. At the time, Guney was making films, there was a ban on the use of Kurdish language in schools, media and all public places across Turkey. Around the time Guney was directing films, Turkish state was in the process of erasing the identity of the Kurds to a point that they started to refer to the Kurds as "Mountain Turks" or "Savage Turks." Guney was deeply troubled by the state oppression around Kurdish bodies so he decided to put Kurdish culture on screen which later put him in extreme odds with the Turkish government. He made his films to be set in the Kurdish areas of Turkey to give his films a Kurdish identity despite its limited freedom on the use of Kurdish language. At that time, Guney was not allowed to tackle Kurdish identity ostensibly and make the state sponsored oppression of the Kurdish the subject matter of his films. Instead, he had to entangle the Kurdish conflict into certain cinematic technique that would refrain from depicting the conflict as the root cause of the suffering and the misery his characters endure.

After the mass migration of the Kurds in the 1980s and 1990s to Europe, Kurdish cinema had a chance to emerge from the diaspora community. After 1990s and within the establishment of Kurdistan Regional Government in Iraq, Kurdish film makers achieved success in producing Kurdish film away from the oppression of the Iraqi government. In Turkey and Syria after 2010 a new era ushered in the Kurdish cinema as Kurds started to gain some of their political rights. In the year 2000 Kurdish film maker Bahmani Ghobadi released A Time for Drunken Horses that was set in a border village between Iran and Iraq. The film won the Camera d'Or at Cannes. The film pivots toward a new era of Kurdish cinema that some critics came to label as the beginning of Kurdish national cinema. It was for the first time Kurdish characters speaking Kurdish language and wearing Kurdish clothes were ostensibly shown on screen won an award in a prestigious international award festival. This research depicts Ghobadi's release of A Time for Drunken Horses as a turning point in the establishment of Kurdish cinema.

The Kurds are one of the largest ethnic group in the world without a state. After the First World War the French and British imperialists carved the states of Turkey, Iraq, Iran and Iran and as the result the Kurds became a minority in each of those nation states. As the Kurds became a minority, Kurdish nationalist entities across all the four countries strived to demand their fundamental rights from the states they lived in. All the four mentioned states have a gruesome history of persecution, denial, oppression and exclusion against the Kurds and other minorities on their land- with the Kurds having gotten the lion share. As Kurds struggled to force the state powers to recognize their fundamental rights among which the right to speak their native language and express their culture, a fragmented sense of identity between what is to be a Kurd in an oppressive state and how the "othering" can be reflected in the "self" was ensued. So it was not only the land that was divided and fragmented but the identity of those who inhabited as well. Furthermore, as Kurds who inhabit beyond the border of each nation states have an incoherent sense of identity and what does it mean to be segregated from your own people under the state apparatuses?

\section{KURDISH NATIONAL IDENTITY IN GUNEY'S YOL AND GHOBADI'S TURTLES CAN FLY:}

Yilmaz Guney's Yol (The Road) starts with a long shot of Imrali prison located on an island with images of muscles humans silhouettes roaming around the prison's courtyard. This scene is followed by the image of a man in isolation through a small window looming over the prison's courtyard, observing the officers distributing newly arrived letters to the prisoners. Soon after, a legislation order from the authority grants the well behaved prisoners a temporary furloughs to visit their families for one week. From the opening scene Guney makes the struggle of the citizens or inhabitants of the prison with the state an overriding theme of the film. He continues to entangle this incessant paradoxical representation of the figures representing the state apparatus and the image of the prisoners. This representation of the prisoners side by side with a figure that represents the state shows how the state keeps the prisoners and the citizens outside the prison as subjects scrutinized to follow the doctrines of the state regardless of their social, economic 
and political histories. After the prisoners are granted furloughs, they embark on a large bus to visit their families. As the film starts to document the life of three prisoners; Seyit Ali, Mehmet Salih and Omer out of all the prisoners, the identity of the three becomes the subject matter of the film in relation to their past, families and culture. Guney throughout the film, doesn't not treat the national identity of the characters as something the characters are dwelling after to recognize or grasp or understand- instead, we the audience are made to see their identity as the root cause of all their problems knowing their social, ethnic and economic background. Guney does not ostensibly addresses how the three prisoners are ethnically from a minority group in Turkey or that being from an economically disadvantaged ethnic group have made them more likely to commit crimes and live in poverty- instead he wants the audience sense the identity of the characters from their struggle. Through this representation, Guney depicts the personhood of the characters in relation to the state, culture and society as something that is constructed and deconstructed by the state periodically contingent upon the circumstances they live through.

The three characters in the films seem to be burdened by the crimes they have committed in the past, the way they have been perceived by the society, and the burden of their poor disadvantaged families. In the film, everyone is a prisoner of something. The men are prisoners of the state, the women are prisoners of the society and the men, the children are prisoners of poverty and conflict, etc. Therefore, None of these characters show any signs of exaltation as they receive the news that they will be furloughed, as if they know that their imprisonment is not limited to the prison they had to live in because of the crimes they have committed. Instead, prison is the societal values, the tradition, and the constant state persecution of the minorities that originally encouraged them to commit crimes and later pushes them to reside in.

The featuring of the prisoners throughout the film until they reach their destination are in long distance shots that put them against the space they inhabit and experience. First, the prisoners are shown in the enclosed walls of a prison courtyard. Later, as they are on the road to reach their final destination, the bus that carries them is often presented in long distant shots that puts it against the space it is passing. The space is the land they are denied to establish their own state on and also is the land conquered by a state that refuses to recognize them as fully human. The bus is constantly stopped by military checkpoints where the identity of the prisoners need to be confirmed by a document in their pocket that recognize them as furloughed state prisoners. The passing of the prisoners throughout the cities and towns of Turkey is hurdled by those random military checkpoints that reminds the prisoners of their imprisonment in the physical prison that recognized them as a person imprisoned for a crime or multiple crime. Throughout the film, Guney incorporates quest of the national identity in the life of the characters subtly. He depicts the chaos and the misery the characters experience as the result of marginalization, denial and dehumanization by the state, and this is where the Kurdshness of the characters are born to be put on display. As the three characters return to their villages, the traditional clothes of the villagers, the rundown neglected houses, and the tough mountain terrains distinctly mark the characters as Kurdish. Kurds as one of the most oppressed ethnic group in Turkey were fighting to have their national identity recognized as Kurdish by the Turkish government at that time. Metaphorically, the prisoners stands for the Kurds who were treated as criminals and were punished for their ethnic identity under Turkish state at the time. When Guney made $\mathrm{Yol}$ in 1982, Turkey was going through multiple political turmoil and internal conflicts. The country was under the law of military dictatorship and the country was struggling with poverty, instability and lack of social order. The right of minorities, especially the Kurds, was extremely limited. The state refused to recognize the Kurds as an ethnically, culturally and traditionally distinct ethnic group from the Turks. The use of Kurdish language was banned. All cultural expressions that displayed the Kurds as a different ethnic group was banned on media. Kurdish music must have been made in secret otherwise, prison time was guaranteed. Kurdish children were forced to assimilate to Turkish culture through an education program that labeled the Kurds as "Mountain Turks" or "Savage Turks". Any form of rebellion or act of activism against state oppression was recognized as an act of terror by the state. For Guney and other Kurdish artists, expressing any form of Kurdish and national identity conspicuously would put them in jail, therefore, they looked for technique through which they could resist against state oppression without facing state prosecution. Guney wrote the screen play for Yol in prison and recruited Serif Goren to direct the film. Later, after Guney escaped prison he edited the film in Switzerland. In Turkey, initially the film was banned due to its portrayal of the Turkish state as an oppressive corrupt authoritarian entity- and later in 1999, the film was only allowed to be screened after the reduction of all the scenes and speeches that alluded to the Kurds as a distinct oppressed ethnic group in Turkey.

Guney in Yol imbeds the Kurdish identity of the characters in the imagery, scenery and the long shots that often put them against a sharp natural background. He derives and creates a unique national identity for the characters through the representation of space, experiencing of culture and the way the characters conceptualize and understand their own existence in relation to the state. As the language of the film is Turkish and none of the characters even for once state that he or she is Kurdish, Guney constructs the Kurdish identity of the characters through certain techniques that makes the struggle of the characters metaphorically stands for the struggle of all the Kurds in Turkey.

In certain scenes in which a large group of people who can only be recognized as Kurdish through their traditional Kurdish attire, are confronting or challenging military men working for the Turkish state. The military men often enter and exit the Kurdish villages with heavy artillery and a grim look on their face. The Kurdish villages are shown as rundown, poor and undeveloped. Every scene which depicts the entering of the military men into the village has been shot in long distant shots where the villagers discern through the military vehicle in silence. When all the three prisoners return back to their families each ends up in a village away from the city in which its people suffers from extreme form of poverty and lack of opportunity. The representation of the poor rundown Kurdish 
villages is contrasted with the image of developed densely populated Turkish cities.

Toward the end of the film Guney creates what best expresses the national identity of the characters in relation to the state. Seyit Ali decides to kill his wife in an attempt of honor killing after realizing that his wife has turned into a prostitute when he was away. In the process of killing, Ali takes his wife and child to climb a tough snowy mountain where his wife ends up dying from hypothermia. As Ali sees his wife struggling in the snow fighting for her life, Ali discern through her struggle as if it is the struggle of an entire nation lurking to survive the vicious natural and man-made circumstances they are doomed to live in. As Ali tries to resuscitate his wife, the scene is shown in long distance shots that put Ali's resuscitation pursuit and his wife's death in a sharp contrast against the snowy mountain they climb. The rough terrains and the vicious weather stands for the hardship and the suffering of the Kurds who historically inhabited in the tough mountainous areas of modern day Turkey. After the death of Ali's wife, the films shifts to Omer's village bordering Syria and Turkey. As he discerns through the border, he imagines his own escape from the country but is unable to do so because the border is littered with mine fields. His town is bordering with another Kurdish town in Syria, Guney again imbeds the Kurdish identity of his character in this scene by ostensibly depicting the separation of the Kurds via imaginary artificial borders on their land.

In The Turtles Can Fly, Ghobadi makes the national identity and the Kurdishness of his characters the subject matter of his films. As the language of the film is Kurdish and the film is set in Kurdistan region, it is not difficult to guess the ethnicity of the characters. However, Ghobadi's representation of their Kurdshness is only to connect it with the characters suffering and brutal existence. All the major characters in The Turtles Can Fly are either kids or are in their early years of adolescence, therefore, their sense of identity hasn't fully emerged or are in the early stages of construction. Like Guney, Ghobadi makes quest of national identity the primary subject of the film as the adversity and the misery they experience is ensued from being a member of an oppressed marginalized ethnic group. Guney and Ghobadi use similar technique to establish and construct an identity for their characters beyond the struggle and suffering they endure. The Turtles Can Fly early scenes feature a refugee camp from a long distance shot that is separated by barbed wires and barricades from the surrounding areas. The setting is "Iraqi Kurdistan- Turkish border." The inhabitants of the refugee camp and the inhabitants outside the refugee camp are all of the same ethnic group; Kurdish. However, belong to different states as they encounter each other. Thus by making the setting of his film a border camp that separates the Kurds from one another Ghobadi depicts the Kurdish identity of the characters as the subject matter of his film through which he ties the struggle of his characters and the dire situation they live in to their Kurdishness.

The film narrates the life of Agrin, a teenage girl from Halabja, who lives in the refugee camp with her handicapped brother and her son Rega whom she conceived after being gang raped by Ba'athist soldiers. Agrin throughout the film struggles with her traumatized past and is unable to refer to Rega as anything more than a taint. Rega is visually impaired. The film starts with Agrin attempting suicide on a top of a mountain. The Kurdish struggle in the film is best shown in Agrin's struggle as the sole prominent female character in the film. Ghobadi uses Agrin's struggle to show that how their Kurdish ethnic identity is the main reason behind their suffering as historically Kurdshness has been a subject of denial, oppression and exclusion. Through Agrin, the audience realize that the characters are suffering only because they are stateless and thus their entire humanity has been compromised as no state entity is willing to acknowledge their existence as humans worthy of fundamental rights. Agrin's death similar to Ali's Wife in Yol takes place on a top of a mountain where her traditional Kurdish clothes are put in focus. Thus, Ghobadi puts his character against the space she inhabits, and in this case, the mountains represent Kurdistan, the rough terrain and the tough life she endured. It is the space, the struggle and clothes that constantly construct Agrin's Kurdish identity for us the audience without having Agrin herself dwelling after. In both Yol and Turtles Can Fly, the characters are barely surviving and are not preoccupies with questions related to their identity, in other words, they do not dwell after their sense of self or who they are. Instead, it is their struggle, suffering and destitution that has us the audience to discern beyond the root cause of their problem, in their case; statelessness and exclusion.

According to Hannah Arendt when millions of human beings were rendered "stateless" and denied the "right to have rights." Statelessness, or the loss of nationality status, she argued, was tantamount to the loss of all rights. In $\mathrm{Yol}$, the characters are rendered stateless on their indigenous land as they are constantly shown in a state of oppression because of their ethnicity. The statelessness of the characters is shown in the way they are perceived by the state as not having any right to express one's national and ethnic identity that cannot become a subject of oppression by the state. (Arendt, 2007. P, 50) Also in The Burden of Our Times Arendt wrote the author states:

Something much more fundamental than freedom and justice, which are rights of citizens, is at stake when belonging to a community into which one is born is no longer a matter of course and not belonging no longer a matter of choice, or when one is placed in a situation where, unless he commits a crime, his treatment by others does not depend on what he does or does not do. This extremity, and nothing else, is the situation of people deprived of human rights. They are deprived, not of the right to freedom, but of the right to action; not of the right to think whatever they please, but of the right to opinion ... We become aware of the existence of a right to have rights (and that means to live in a framework where one is judged by one's actions and opinions) and a right to belong to some kind of organized community, only when millions of people emerge who had lost and could not regain these rights because of the new global political situation. (Arendt, 1951.P, 177).According to Arendt drawing a strict line that could categorize a group of people or community as either refugee, stateless, citizen, etc. is fluid.

Arendt always insisted that among the root causes of totalitarianism was the collapse of the nation-state system in Europe during the two world wars. The totalitarian disregard for human life and the eventual treatment of human beings as "superfluous" entities began. Similar things can be seen 
happening in both films where the identity and the personhood of the characters become an excuse through which the state dehumanizes the persons in the films and reduce them to entities rendered as less human or worthy of death, torture and exclusion. Thus, simultaneously, the Kurdish identity of the characters are sensed by us the audience through this representation of the dehumanized characters. The characters in both of the films feel helpless to have any of their rights granted to them by the state. This contrast of an oppressive dominant power entity looming over the helpless without-any-right characters results in the emergence of a Kurdish national identity marked by suffering, exclusion, dehumanization and death.

\section{CONCLUSION}

In both Yol and The Turtles Can Fly the power dynamics between the state and the people are rendered in relation to the insignificance of the life of the people in the face of extremely brutal powerful states. As both films progress, the audience realize the existence and the life of the people are reduced to less of an entity that can be seen as human in the eyes of state. Thus the identity of the characters that is constructed by the state as less or sub-human beings seen on display by the audience. The characters in none of the films dwell on their own sense of identity and are immersed in their sense of despair and loss as they are experiencing their tragic life. However, the directors with their unique techniques of contrasting space and characters, long distance shots and expressive imagery imbed the Kurdishness of the characters in their films and put it on screen to be seen, felt and experienced. Thus the "superfluous," in Arendt's words, entities in the films are humans who are first dehumanized by the state and deprived from much of their human rights due to their statelessness.

\section{REFERENCES}

Arendt, H. (2007). The origins of totalitarianism (pp. 417-443). Duke University Press.

Arendt, H. (1951). The burden of our time. Secker \& Warburg.

Anderson, B. (2020). Imagined Communities: Reflections on the origin and spread of nationalism. In The New Social Theory Reader (pp. 282-288). Routledge.

Ghobadi, B. (2002). Time For Drunken Horses, Tartan Video.

Hjort, M., Mackenzie, S., \& Fulford, M. (2000). Cinema and nation. Psychology Press.

Koçer, Suncem. "Kurdish cinema as a transnational discourse genre: Cinematic visibility, cultural resilience, and political agency." International Journal of Middle East Studies 46.3 (2014): 473-488.

Güney,1982, ed. Yol. Films sans frontiers.

Vitali, V., \& Willemen, P. (Eds.). (2019). Theorising national cinema. Bloomsbury Publishing. 